\title{
EL SUSTRATO ARÁBIGO-GRANADINO EN LA FORMACIÓN DE LOS DIALECTOS ORIENTALES DEL ANDALUZ*
}

Cuando una lengua penetra en un territorio nuevo, desplazando la que anteriormente se hablaba allí tras convivir con ella algún tiempo, y a continuación desarrolla en aquella región nuevos rasgos fonéticos, fonológicos, morfológicos, léxicos o sintácticos, conviene examinar la posibilidad de que dichas innovaciones se deban a la influencia de la lengua desplazada (influencia de sustrato).

Estas condiciones se dan en Andalucía Oriental, ya que el castellano llevado allí a partir de su reconquista (1492) sufrió importantes cambios fonéticos y fonológicos, entre otros: la debilitación y caída de todas las consonantes finales de sílaba, el yeísmo, el desarrollo de un sistema de variación armónica de las vocales para distinguir el singular del plural, etc. Sin embargo, hasta ahora apenas se ha planteado la posibilidad de que el sustrato arábigo-granadino actuara en la evolución de estos rasgos.

La falta de interés por una explicación sustratista se debe seguramente a dos factores. En primer lugar, como señala A. Zamora Vicente con referencia a diversas características de la pronunciación andaluza: «Por lo general, se puede decir que estos fenómenos existen igualmente en otras regiones españolas, en mayor o menor grado», aunque reconoce

* Quiero expresar mi gratitud a los doctores J. Muñoz Garrigós y A. Carmona González por haber leído el manuscrito de este trabajo, indicándome numerosas correcciones y mejoras. 
que resulta imposible «establecer relación alguna de dependencia o parentesco histórico con las comarcas andaluzas»'. Se tiende, por lo tanto, a considerar que la pronunciación andaluza resulta principalmente de una evolución interna del castellano en tierras meridionales, provocada o acelerada por la abigarrada procedencia de los repobladores cristianos.

El segundo motivo por el que no se ha considerado seriamente la posibilidad de una actuación del sustrato arábigo es sin duda porque no se han detectado en la fonética árabe, ni particularmente en la hispano-árabe, los rasgos típicos de la pronunciación andaluza. Naturalmente, la primera condición para poder atribuir una serie de cambios fonéticos, o fonológicos, a la influencia de una lengua ajena es que estos rasgos existan en aquella lengua. Y tal no parecía ser el caso.

En este trabajo se intenta demostrar que el árabe granadino vulgar de los siglos XV-XVI había desarrollado características de pronunciación que lo distinguen radicalmente del hispano-árabe culto o semi-culto que conocemos a través de los textos escritos. Partiendo de esta variante tardía del árabe hispánico, que es precisamente la que entró en contacto directo con el castellano durante el período de formación del andaluz oriental (1492-1570), se plantea la posibilidad de que diversos rasgos del castellano meridional se debieran a la influencia de este sustrato arábigo-granadino.

FunNTES. Con el fin de determinar las características de la pronunciación vulgar del árabe granadino tardío se han examinado distintas fuentes onomásticas; en ellas los escribanos castellanos anotaron, tal como los óan en boca de los mudéjares/moriscos, una amplia gama de antropónimos y topónimos granadinos y almerienses. Para conocer la pronunciación del árabe hablado en la ciudad de Granada y su comarca, al comienzo y al final del período de convivencia con el castellano, se ha utilizado especialmente el abundante material onomástico del Libro de Habices de las Mezquitas de la ciudad de Granada y sus alquerias ${ }^{2}$, redactado en 1505, y el acta de una Visita a todas las casas del Albaicín en el año 15693 , cuyo texto recoge, entre otros datos, los nombres y apellidos de todos los moriscos que tenían casas allí. Para Almería se

1 A. Zamoren Vicente, Dialectologia Espariola, B. R. H. III, 8, pág. 287.

2 M. C. Villanubva Rioo, Habices de las Mezquitas de la ciudad de Granada $y$ sus alquerias, Inst. Hisp.-Ar. de Cultura, Madrid, 1961.

3 J. MARTtNez RUIz, Visita a todas las casas del Albaicin en el año 1569, III, San Gregorio, San Luis, San Nicolds (antroponimia, etnologia y lingütstica), Cuadernos de la Alhambra 19-20 (1983-4), págs. 247-283. 


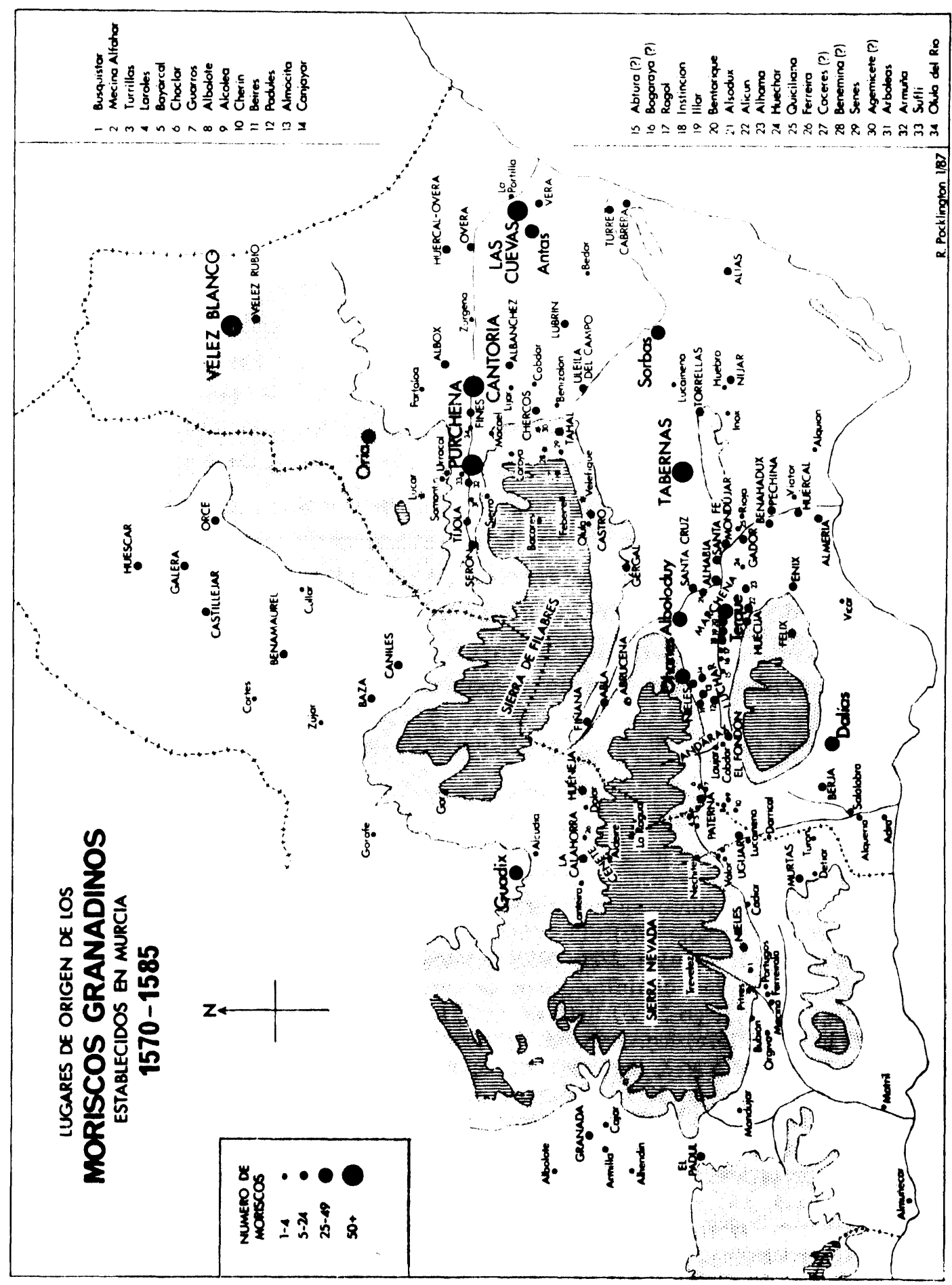

LXVI, 1.0-2.0 -6 
empleó el Libro del Repartimiento de Almería (1498-1504) ${ }^{4}$, y los padrones de moriscos granadinos establecidos en Murcia tras la expulsión de $1570^{5}$, ya que la mayoría de los moriscos que vinieron a Murcia eran oriundos de la provincia de Almería (ver mapa). Resulta, además, de excepcional interés para conocer la pronunciación morisca del castellano el manuscrito original del Memorial ${ }^{6}$ que el morisco granadino F. Núñez Muley redactó en 1567, suplicando la derogación de la Pragmática Real que prohibía definitivamente el uso de la lengua y costumbres arábigo-granadinas.

Por otra parte, una vez determinados los rasgos esenciales de la pronunciación del árabe granadino tardío, fue posible localizar casos esporádicos de los mismos en el hispano-árabe de los siglos anteriores, utilizando sobre todo el fundamental estudio de F. Corriente, A grammatical sketch of the Spanish Arabic dialect bundle ${ }^{7}$, pero también el material arábigo-valenciano aportado por M. C. Barceló Torres ${ }^{8}$, la obra de L. Seco de Lucena intitulada Topónimos árabes identificados ${ }^{9}$, que indica las grafías árabes de un buen número de topónimos granadinos mencionados en el Libro de Habices, y el estudio De la Alpujarra ${ }^{10}$ de M. Gómez-Moreno que recoge las formas árabes de los nombres de diversos pueblos alpujarreños, lugares de origen de muchos de los moriscos avencidados en Murcia a partir de 1570.

4 C. Segura Grafĩo, El Libro del Repartimiento de Almeria, Univ. Complutense, Madrid, 1982.

5' Durante los primeros quince años de su estancia en Murcia (1570-85) se confeccionaron perídicamente censos meticulosos, en los cuales debían figurar: «los moriscos libres y catiuos del Reino de Granada, sin dexar ninguno, poniendo los nombres y señas y edades de cada uno, y la tierra do son naturales segund quellos lo dixeren, como su magestad manda (Arch. Mun. de Murcia, leg. 3905, pliego 2, fol. 33 verso; 1573). La mayoría de estos padrones se conservan en el Archivo Municipal: legajos 2721, 3082 y 3905, y el libro núm. 33, armario 1. Para hacer referencia a las distintas listas se emplearán las siguientes letras: $A$ ) lista de 1571, leg. 3082, pliego 2 ; B) lista de 1573, leg. 3905, pl. 2; C) lista de 1575, leg. 3082, pl. 5; D) lista de 1576, leg. 3905, pl. 1; E) lista de 1578, leg. 3905, pl. 4; F) lista de 1585, leg. 3905, pls. 5 y 7, leg. 3082, pl. 6; G) lista de 1571 (Lorca), leg. 3082, pl. 3; H) diversos papeles de 1571, leg. 3905, pl. 5; L) lista de 1583-4 (Murcia), libro 33, armario 1; $M$ ) lista de 1571 (Mazarrón), leg. 3082, pl. 4; P) copias de pasaportes extendidos a moriscos en 1582-3, leg. 2721. En el legajo 3082, pliego 1, se encuentra el indice, por orden alfabético, de todos los moriscos alistados en el libro 33.

6 K. GaRRAD, The original memorial of don Francisco Núñez Muley, Atlante II, núm. 4 (octubre 1954), págs. 199-226.

7 F. CORRIENTE, A grammatical sketch of the Spanish Arabic dialect bundle, Inst. Hisp.-Ar. de Cultura, Madrid, 1977.

8 M. C. Barceló Torres, Minorias islámicas en el País Valenciano, Univ. de Valencia / Inst. Hisp.-Ar. de Cultura, 1984.

9 L. SвCO DE LUCRNA, Topónimos árabes identificados, Universidad de Granada, 1974.

10 M. Gomez-Moreno, De la Alpujarra, Al-Andalus XVI (1951), págs. 17-36. 
Planteamiento. El análisis de las transcripciones castellanas de topónimos y antropónimos citados por los moriscos granadinos permite determinar los rasgos más destacados de su pronunciación, la cual muestra escasas variaciones entre 1500 y 1570. La característica más notable, desde todos los puntos de vista, es la reiterada confusión y pérdida de todas las consonantes finales de sílaba, tanto en posición interior como final, y la ultracorrección de esta misma tendencia con la inserción o agregación de consonantes implosivas anti-etimológicas. Dado que éste es también uno de los rasgos más destacados del andaluz oriental actual, debemos considerar seriamente la posibilidad de que el sustrato arábigo-granadino actuara en su desarrollo, máxime si se tiene en cuenta que en el árabe granadino esta característica ya se encontraba totalmente generalizada en el año 1500, cuando los dialectos castellanos apenas habían iniciado el mismo camino.

No obstante, ésta no es la única peculiaridad fonética o fonológica que comparten el andaluz oriental y el árabe granadino tardío. Los moriscos granadinos también debían de ser yeístas. Sabido es que la lengua árabe no conoce la elle, y que un sujeto de lengua materna árabe, al hablar romance o al emplear préstamos léxicos tomados del romance, utilizaba el grupo - $l y$ - para sustituirla. Pues bien, de acuerdo con las reglas de división silábica en el árabe, la $l$ de este grupo se encontraba en posición implosiva, y por lo tanto tendería a desaparecer en el árabe granadino tardío como cualquier otra consonante implosiva. Así, el morisco granadino, en lugar de decir $-l y$-, diría - $y$ - sola como equivalente de la - $l l$ - castellana, produciendo el efecto del yeísmo. Existen motivos para creer que el yeísmo andaluz se propagó desde Andalucía oriental.

Otro rasgo sumamente original de las hablas orientales del andaluz, que ya se ha extendido a zonas limítrofes, es la variación en armonía de todas las vocales de la palabra para distinguir el singular del plural y para mantener otras oposiciones anteriormente determinadas por consonantes finales cuya funcionalidad se encuentra hoy considerablemente mermada: /djẹntẹ/ - «diente», /djęntę/ - «dientes», etc. El estudio del material onomástico de los padrones murcianos demuestra que los moriscos granadinos también abrían y cerraban en armonía las vocales de las palabras, y que el grado de abertura podría variar según la consonante final, de la misma forma que en el andaluz oriental. La modificación ạlofónica de las vocales de acuerdo con el entorno consonántico es una de las características más notables de la fonética árabe; con la debilitación y caída de las consonantes implosivas en el árabe granadino tardío esta variación vocálica acaso ya había adquirido una función 
fonológica en dicho dialecto árabe, igual que la tiene en el andaluz oriental actual.

También tienen correspondencia en el árabe granadino tardío al menos otras tres características del andaluz oriental. La neutralización granadina de $l / r$ explosivas agrupadas (blanco $>$ branco, planta $>$ pranta, etcétera), aislada geográficamente del área portuguesa, puede ponerse en relación con la no existencia de estos grupos en el árabe; es significativo que el Memorial del morisco granadino Núñez Muley ya contiene algunos ejemplos. La conversión de - $a$ final en /e/, detectada esporádicamente en diversas partes de Andalucía Oriental y de manera sistemática en el Valle de Lecrín, recuerda instancias del mismo fenómeno en la antroponimia musulmana del Repartimiento de Almería. Y la conversión de $b$ - en $f$-por una $-s$ implosiva aspirada anterior (las botas $>$ lah fotah, etc.), desarrollo originalísimo, tiene asimismo antecedentes hispano-árabes.

Seis importantes rasgos fonéticos y fonológicos del andaluz oriental tienen, entonces, precedentes en el árabe granadino tardío. De tratarse solamente de una o dos características comunes, acaso se podría achacarlo a la casualidad. Pero en vista del crecido número de correspondencias, no creo que pueda haber otra explicación que la de una profundísima influencia del sustrato arábigo-granadino sobre el castellano importado al Reino de Granada a partir de su reconquista. Sin embargo, antes de examinar más detenidamente esta posibilidad, es preciso escrutar la evidencia de que estos seis rasgos realmente aparecen en el árabe granadino tardío, sobre cuya aserción descansa todo el peso de la hipótesis.

\section{DEBILITACION Y CAIDA DE LAS CONSONANTES IMPLOSIVAS}

Uno de los rasgos más llamativos de la pronunciación del andaluz oriental es sin duda la debilitación, aspiración, confusión, caída y empleo ultracorrecto de todas las consonantes finales de sílaba, en mayor o menor grado, tanto en posición interior como al término de la palabra.

Esta neutralización fonológica de la consonante implosiva podría considerarse el resultado de haberse llevado hasta sus útlimas consecuencias en tierras meridionales la ley fonológica del español establecida por Amado Alonso ", según la cual en el castellano las consonantes

11 A. Alonso, Una ley fonológica del español, en sus Estudios Lingüísticos Temas Españoles, B. R. H. II, 2, Gredos, Madrid, 1974, págs. 237-249. 
pierden, en posición implosiva, parte de su capacidad diferenciadora. En el andaluz estas consonantes llegan, en muchos casos, a perder toda su capacidad diferenciadora, de modo que en algunas de sus funciones más importantes han sido reemplazadas por un sistema de matización de las vocales, por ejemplo para distinguir el singular del plural. No obstante, aunque un desarrollo interno castellano-dialectal del fenómeno sería aceptable metodológicamente, no podemos hacer caso omiso de la presencia del mismo rasgo como característica predominante de la lengua hablada en las mismas tierras antes de que se impusiera definitivamente el castellano.

Los padrones murcianos demuestran que los moriscos almerienses debilitaban y confundían sistemáticamente las consonantes finales de sílaba. Por ejemplo, el morisco Alonso Alcarfí se llama, en los distintos registros, Alcarfi, Alcafi, Alcarfin, Alquerpi, El Carfin ${ }^{12}$. Los dos Huércal almerienses se denominan Huercal, Huercar, Huecar, Huerca ${ }^{13}$. Albanchez es Albanchez, Albanches, Albanchen, Albechin, El Beynchin, Albechinze ${ }^{14}$. Alboloduy, en árabe Buludūad, se llama Albuludud, Albuludu, El Buludux, El Buluduy ${ }^{15}$. Una serie de topónimos habitualmente recogidos con $-n,-r,-s$, 0 - $t$ finales modifican o pierden esta consonante ${ }^{16}$. Canjáyar aparece una vez como Cayjayar, y otra como Caynjayar con la primera "y" tachada posteriormente; Paterna del Río es una vez Pasternas con la primera $-s$ luego tachada; Diego Gomariz de las Cuevas figura como Diego Cosmarin de las Queuas en una lista ${ }^{17}$. Etcétera.

El estudio del caudal onomástico de la Visita a todas las casas del Albaicín en el año 1569 revela esencialmente los mismos rasgos en la pronunciación de los moriscos de la ciudad de Granada ${ }^{18}$. El Memorial

12 B5r, L46v, B54v, B7v, D15r.

13 Huercal (passim); los demás: B50v, L124v, B3r, etc.

14 B9r, B37v, F5v, C14v, L153v, C2v.

$15 \mathrm{D} 13 \mathrm{r}, \mathrm{D} 17 \mathrm{r}, \mathrm{C} 18 \mathrm{r}, \mathrm{B} 9 \mathrm{v}$. El paso del árabe $d$ al castellano $-y$ ocurrió dentro del árabe, de acuerdo con estos datos, y atestigua la gran flexibilidad de la conso. nante implosiva en el dialecto granadino del hispano-árabe.

16 El Fondón es El Fondo M2v, El Fondol B6r; Lubrín es Lobril E5r, Lebrill L5v. Canjáyar es Canjaya D21r, B3r, Canxaia B15r; Gádor es Gado A9r, B6v, C12r; Huéchar es Guechan B37r; Ugijar es Uxija L10r, Ugija L155v; Válor es Valos L8v; Antas, Chercos, Dalías, Guarros, Murtas, Nieles, Sorbas y Tabernas son, excepcionalmente, Anta L176r, L190v, Cherco L68r, Chirco L131r, Hierco L131r, Dalia A9v, D11v, L17r, Guarro B3v, Murta B34r, L56v, Nala B9v, Nialda L3v, L144r, Sorua D23r, L184v, Tauerna B49r, B50v, B52r, Taberna D19r; un pequeño lugar de la sierra de Filabres se denomina Agemiçet B27r, Agimiçet B27v, pero Agimiçi B27r; el morisco Diego Alabiat B55r, cuyo apellido es el árabe al-Abyad «el Blancon, se llama normalmente Diego Labiar B24v, D8r, F15v.

17 M3v, M3v, D7r, F11v.

18 Por ejemplo, el apellido Almaulud, Maulud (257) aparece también como Mautu (256). Lope Rincoti (261) indudablemente lleva la nisba Riqüfl ade Ricote (Murcta)». 
del morisco Núñez Muley (1567) - testimonio granadino de especial interés- contiene un buen número de casos de confusión y pérdida de làs consonantes implosivas. La voz muftí aparece en plural como "almotís" (204) y «mostís» (215): la -f etimológica se pierde o se convierte en $-s$. La palabra eclesiástica a veces adquiere una -s anti-etimológica: «esclesiástica» $(212,214)$, «escresiástica» (212). El infinitivo puede trocar su - $r$ final por $-d$ : "lo que se hará en quered efectuar esta pregmática» (211), «me dixo que si vestían áuito castellano las mugeres, podría de allí resultad franquesas o libertades» (212), "el dicho alguzil no la quiso dexar ni soltad, [y] lo mataron" (213). Hay también algunos casos de plurales sin $-s$, aunque no se puede excluir del todo que se deban a la interferencia sintáctica de la lengua materna árabe del autor: "y otrás cosas que en la dicha premática [son] contenida y eligida" (214), "y en su tiempo heran las fiestas del Corpus Cristi tan solenes y tan sonada como hera la de aquí" (215). Y aún se pueden añadir bastantes ejemplos más ${ }^{19}$, como los ya conocidos trueques $-l /: r$ de este autor (p. ej. leartad, alçobispo, silben «sirven», bulla «burla», calbonero).

Las tres fuentes utilizadas hasta aquí sólo permiten sacar conclusiones acerca de la pronunciación arábigo-granadina en una época muy tardía (1567-1585). De no disponer de datos más antiguos, se podría oponer a nuestra hipótesis el reparo de que los moriscos habrían podido aprender este rasgo de los castellanos, habiéndolo desarrollado éstos en su propio lenguaje durante los setenta años transcurridos desde la Reconquista. Pero la presencia del mismo rasgo en fuentes del año 1500 excluye definitivamente esta posibilidad.

Son abundantísimos los casos de debilitación, caída y ultracorrección de la consonante implosiva en el material onomástico hispano-árabe del Repartimiento de Almería (1498-1504). Uno de los ejemplos más notables es el nombre propio Yūsuf, el cual se vocaliza normalmente $Y u \overline{s a f}$ en el hispano-árabe, y aparece en este texto casi exclusivamente bajo la forma $Y u c ̧ a$, con pérdida de la $-f$ final ${ }^{20}$. El nombre $S a^{\bullet} i d$, que

El Mudexal (266) será «el Mudéjar». Frente a Aben Lupe (268) hallamos Abelupa (269). Hernando Gordomian (274) llevará el apellido hispano-árabe Quzmān, famoso por el poeta Ibn Quzmān, con o epentética entre $z-m$, y $-r$ implosiva anti-etimológica: ‘Qurzumān. El árabe Futūh aparece como Foto (276), Fotoy $(272,273,283)$, y Foton (283). Al lado de Bernabé Duzonze (280) está Elvira Duzoza (281). Etc.

19 La palabra instrumentos se escribe normalmente kestrumentos», pero también encontramos tres veces «los trumentos» (215); por otra parte, el nombre de la ciudad de Tremecén figura como «Estremecén* (211) (aquí el grupo inicial $\mathrm{Tr}$ requiere una vocal de apoyo en árabe ${ }^{\star} E$ tr -, detrás de la cual se ha intercalado una $-s$ anti-etimológica). La voz cesión se escribe tres veces «sebesión* (208), lo que presupone una forma intermedia ${ }^{*}$ cebsion.

is Págs. 123, 129, 162, 166, 168, 183, 191, 196, etc. Excepcionalmente hallamos 
debió pronunciarse /Sáyd/, podía perder cualquiera de las dos implosivas: Çaid, Çay, Çad ${ }^{21}$. El apellido Alfarnay asimismo pierde $-r$ y $-y$ : Alfanay, Alfani, Farna ${ }^{22}$. La nisba Alcabsi (309) muestra diversas variantes: Calçis, Alcauzi, Alcarci, Alcabzis ${ }^{23}$. El nombre Alhogey, probablemente el diminutivo al-Huyayy de $H \bar{a} \bar{y} \hat{y}$ "Peregrino a la Meca», aparece con diversas consonantes finales: Alhogeis, Alhogeir, Alhoge, Alhoges, Alhager ${ }^{24}$. Etc., etc.

En Granada encontramos exactamente el mismo fenómeno. Numerosos topónimos cuyas grafías árabes fueron determinadas por L. Seco de Lucena en su libro Topónimos Arabes Identificados (TAI) aparecen en el Libro de Habices ( $\mathrm{HAB}$ ) con sus consonantes implosivas ya transformadas o perdidas ${ }^{25}$. Por otra parte, el estudio crítico de la antroponimia y toponimia del dicho Libro de Habices permite detectar las mismas tendencias, tanto en nombres cuya etimología resulta transparente, como en los que se repiten bajo distintas grafías ${ }^{20}$.

Desde luego sería sorprendente que un fenómeno de tal importancia y envergadura se manifestara de repente en el árabe granadino hacia el año 1492, y de hecho existen bastantes testimonios similares en la documentación de los siglos anteriores, aunque no se hayan recogido sistemáticamente hasta ahora.

la forma clásica Yüsuf por cultismo: Yuçuf Ben Maçod (162) frente a Yuça Ben Maçod (162), Yusuf Alhagi (300) frente a Yuça Alhagi (406, 408); y Yuçab Açamariz (443) - forma popular cuya $-b$ recuerda la $-f$ etimológica- al lado de Yuça Açamariz (338).

21 Çad Albacar (421, 422, 427) pero Çaide Albacar (422); Ali Çaid (487) al lado de Ali Çay (328, 361,362, 422...); Aben Çaide (284), Aben Çay $(254,267,355)$; Çad Arraquique (230, 433), Çaid Arraquique (432), Çaide Arraqui (231).

22 Págs. 215, 259; 495; 189.

23 Págs. 336; 357; 375; 462.

24 Págs. 258; 157; 155, 313; 126; 127.

25 El pago de Alfarrá, denominado Hauz Alfarrá en HAB, es al-Farrān en textos árabes (TAI, pág. 10). Algader, en árabe al-Gadirr, es una vez Algadeb en HAB (TAI, pág. 11). Cujar, en árabe Qulyar, es ya Cuxar en HAB, con pérdida de la $-l$ implosiva (TAI, pág. 33). Darjuyel, en árabe Där al-Huwayt "Casa del Pececillo», es ya Daralhuyel al lado de Daralhueyed en HAB (TAI, págs. 36-7). Tarramonta, cuya grafía árabe vacila entre Tarramūrta y Tanramurta, es Tarramonte y Tarramuta en HAB (TAI, pág. 74). Etcc.

26 El nombre 'Abd al-Rahmān pierde su -n implosiva: Abdarrahami (149n1), Adurrami (346), Abdurrami (348). 'Abd al-"Aziz convierte su -z en -r: Abdulazir (203). -Abd al-Raziq puede perder su -q final: Abdurrazic (266, 268), Adurrazi (294), $A b$ durraze (298). Zacaría Alcozili (78) es Zacaría Alcorzili con -r (82). El diminutivo árabe al-Qunaytar/-ir wel Puentecillo» aparece a menudo sin su $-r$ final: Alconayte (337), Alconaite (95), Alconaytal (78n1). El topónimo Andar Aben Taher (169), del árabe Andar Ibn Tăhir «Era de Ibn Tāhir», es Andar Aben Tahe (190). El nombre propio Sulayman aparece como Çenleyma (231n7), Çuleyma $(338 \mathrm{n} 5,338 \mathrm{n} 11,352 \mathrm{nb}$, 353n8). Etc. 
La confusión de - $m /-n$ implosivas está bien atestiguada desde muy temprano en el hispano-árabe. F. Corriente señala que este fenómeno abunda en el Vocabulista de P. de Alcalá, donde no siempre se puede atribuir a errores de imprenta o del autor, y en el Vocabulista in Arábico, léxico del hispano-árabe levantino del s. XIII ${ }^{27}$. J. Corominas, tras llegar a las mismas conclusiones acerca de las transcripciones de P. de Alcalá, añade varios casos de arabismos catalanes que remontan a raíces con $-m /-n$ intercambiadas (p. ej. almugatèn, magatzem del árabe al-muqaddam, majzan), y considera que «l'àrab vulgar de la Península pronunciava la $-m$ final de mot com a $-n$, igual que el castellà d'avui» ${ }^{28}$. M. C. Barceló Torres halló trueques $-m /-n$, y algún caso de pérdida de $-m$, en los textos arábigo-valencianos ${ }^{29}$. Un ejemplo especialmente significativo del rasgo, por su claridad y temprana fecha, constituyen las monedas acuñadas a nombre del eslavo Jayrān, señor de Almería y de otros territorios del sureste peninsular a comienzos del s. XI, en las cuales se le llama Jayrām, con $-m$ en lugar de $-n$, en el año 1013-14 ${ }^{30}$.

La debilitación y pérdida de $-r$ y $-l$ son también antiguas. J. M. Pabón ya indicó que el topónimo Morón (Sevilla), en fuentes árabes inicialmente Mawrür (lat. MAURÓRUM), se transcribe en otros textos Mawrūn ${ }^{31}$. La voz castellana alfanje, del hisp.-ár. al-jaryyal, es ya "alfange» sin la $-l$ final en un texto de $1272-84$ 32; la pérdida ha de atribuirse a la pronunciación árabe ya que el castellano aún mantenía estas consonantes con relativa firmeza en aquellas fechas. F. Corriente denuncia diversas instancias de la caída de $-r$ implosiva, su conversión en $-y$, y numerosos trueques de $-r /-l$ en posición final de sílaba ${ }^{33}$, y M. C. Barceló detectó rasgos similares en la documentación arábigo-valenciana ${ }^{34}$. Aparecen interesantes casos de ultracorrección en arabismos toponímicos murcianos del s. XIII donde se intercala $-r$ anti-etimológica ${ }^{35}$.

Es posible reunir testimonios similares para la mayoría de las consonantes en posisión implosiva en material linguístico hispano-árabe,

\footnotetext{
27 F. CoRriente, Sketch, pág. 36, secc. 2.4.2.

28 J. Coromings, Entre dos llenguatges, Curial, Barcelona, 1977, tomo III, pág. 104.

29 Minorías islámicas, op. cit., pág. 170, secc. 4.2.2.3.

30 J. J. RodrfGURz LORENTE, Aportación al estudio numismático de las taifas del califato. - Los territorios del eslavo eunuco Jayrän, Al-Qanțara II (1981), págs. 453-5.

31 J. M. PABON, Sobre los nombres de la «villa» romana en Andalucía, en Est. ded. a D. Ramón Menéndez Pidal, IV (1953) (págs. 87-165), pág. 102, nota 1.

32 J. Corominas \& J. A. Pascual, Diccionario crítico etimológico castellano $e$ hispdnico, Gredos, Madrid, 1980, sub voce.

33 Sketch, pág. 43, secciones 2.11.1 y 2.11.2, y pág. 52, secc. 2.20.1.

34 Minorías isldmicas, págs. 172-5, secciones 4.2.2.11 y 4.2.2.21.

35 Ver mis Notas de toponimia arabigo-murciana, Sharq al-Andalus 3 (en prensa), s. v. Bujércal.
} 
como se puede comprobar en la sección correspondiente del libro de Corriente. Así, respecto a la $-n$, este autor observa que tendía a ser asimilada o desaparecer en el árabe hispánico. La conversión de - $b$ en - $f$ y viceversa también se encuentra a menudo en estas fuentes, y está bien documentada en préstamos léxicos al romance peninsular (p. ej. garrofa «algarroba», garrofero «algarrobo», de jarrūb(a); el cat. ant. mostassaf «almotacén» del hisp.-ár. muḥtasab). Etc., etc., etc.

\section{YEISMO}

Si hasta ahora nadie ha intentado relacionar el yeísmo meridional con el sustrato árabe, a pesar de que la lengua árabe no conoce la $/ \mathrm{l} /$, y un sujeto de lengua materna árabe la encuentra muy difícil de pronunciar, es porque se sabe que los hispano-árabes aljamiados sistemáticamente empleaban el grupo $-l y$-, y no la $-y$ - sola, para sustituirla ${ }^{36}$. Además, parecería probar que los moriscos no eran yeístas la constante ausencia del yeísmo como rasgo característico de la pronunciación morisca en las obras dramáticas de los siglos XVI-XVII, así como el hecho de que, durante la Guerra de Granada (1568-70), se emplease la palabra cebolla para identificar a los moriscos granadinos de lengua materna árabe, quienes no podían evitar de pronunciarla xebolia.

Sin embargo, si, como acabamos de demostrar, los moriscos granadinos articulaban débil o nulamente las consonantes finales de sílaba, es evidente que tenderían al yeísmo, puesto que en la combinación -lyla consonante $l$ se encuentra en posición implosiva, y por lo tanto propensa a perderse, dejando $-y$ - en lugar de la / $/ /$ castellana original. Se trata de un yeísmo indirecto, pero el resultado es el mismo.

Para verificar la certeza de esta hipótesis debemos, en primer lugar, comprobar dos hechos: 1) que la $l$ en la combinación -ly-se encontraba realmente en posición implosiva, o, dicho de otra manera, demostrar que la $y$ arábigo-granadina tenía pleno valor consonántico, de modo que la $l$, o cualquier otra consonante, situada delante de ella se encontraba en posición implosiva, y por tanto destinada a debilitarse, trocarse por otra consonante o perderse; 2) hallar casos claros de yeísmo en la pronunciación de los moriscos granadinos y otros hispano-árabes aljamiados.

36 A. GALMES DE FUENTES, Lle-yeismo y otras cuestiones lingüisticas en un relato morisco del siglo XVII, en Est. ded. a D. Ramón Menéndez Pidal, VII, 1956, páginas 283-6. 
Para demostrar el primer punto, debemos localizar en la documentación casos de la variación o pérdida de consonantes seguidas de /i / J. M. Pabón ya encontró algunos indicios de $/ \mathrm{ri} />/ \mathrm{y} /$ en la toponimia andaluza: Cantoria, cuya $r$ está comprobada en textos árabes, se escribe Cantoya en un texto castellano de 1514, y los topónimos Ortuyena y Chincoya parecen remontar a étimos latinos con /ri/: (H)ORTORIUS y SINCORIUs ${ }^{37}$. El topónimo valenciano Polinyà es Bunirya en un documento árabe de $1578{ }^{38}$. Y encontramos un caso muy claro del fenómeno en los padrones murcianos: el apellido Cariaga, llevado a Almería por repobladores castellanos ${ }^{39}$, fue adoptado por una familia de moriscos naturales de Terque, quienes vinieron a instalarse en Murcia tras la Guerra de Granada. En castellano la $r$ se encontraba al comienzo de su sílaba (Ca-riá-ga), pero en la pronunciación morisca la división silábica debió ser Car-yá-ga ya que en las formas documentadas en Murcia la $r$ a veces se reduplicaba, y otras veces se podía perder: Bartolomé de Cariaga (L109v), Bartolomé Descariaca (B46v), Bartolomé Carriaca o Queriaca (E13r), Bartolomé de Cayaca (D16v, dos veces).

Son más frecuentes, y de mayor interés como se verá, las alteraciones de $-n$ ante $y$. El topónimo Armuña de Almanzora (Almería), en árabe al-Munya «el Huerto", figura una vez como Almuria (B18r), con la $r$ corregida posteriormente en $n$. El elemento onomástico Aben (ár. Ibn "Hijo de») a veces pierde su $-n$ ante $y$ : Martín Abeyaix (Visita, 265) del árabe Ibn $Y a^{\bullet} \bar{i}$, y Abulfarax Abeyuça (HAB, 44n2) del hispano-árabe Ibn Yūsaf. Encontramos un ejemplo curioso de la ultracorrección de la misma tendencia en el Memorial de Núñez Muley, en el cual se escribe una vez vinieron en lugar de vieron:

$\mathrm{Y}$ anque algunos de los naturales se agrabiavan en seruir a Su Magt. con tanto número demás de los dichos veinte y un ducados de ordinario, el dicho Marqués de Mondéjar y los prençipales desta çibdad y de fuera della vinieron que hera justo seruir a Su Magt., ... 40.

Debido a que el árabe no tolera los diptongos puros ni los grupos iniciales de consonantes, un sujeto de lengua materna árabe pronunciará el castellano vieron como /biyéron/, donde la inserción de una - $n$ anti-etimológica delante de la $y$ dará el resultado /binyéron/, es decir

37 Op. cit., pág. 102, nota 1.

38 Minorias islámicas', pág. 172, secc. 4.2.2.11, y doc. núm. 185. (220).

39 Repartimiento de Almeria: "Martín de Cariaga» (181), "Ochoa de Cariaga"

40 Págs. 208-9 de la edición de K. Garrad, quien corrige «[con]vinieron», y además intercala "y» delante de «el dicho Marqués»; no creo que sea necesario corregir el texto de esta forma. 
"vinieron». Por causa de esto los moriscos granadinos debían confundir los verbos ver y venir, lo que explica la forma convía por convenía en otro pasaje ${ }^{41}$.

Como se sabe, de la misma manera que los árabes empleaban - $l y$ para representar la $/ l /$, utilizaban la combinación - $n y$ - como sustituto de la $\tilde{n}$ castellana, ya que la lengua árabe tampoco tiene este sonido palatal. Los castellanos eran conscientes de esta equivalencia porque en muchas ocasiones empleaban su $\tilde{n}$ para representar el grupo $n y$ de nombres y voces tomadas del árabe (p. ej. Almuña $<$ al-Munya). Ahora, cuando en la pronunciación morisca la $-n$ implosiva dejaba de oírse delante de una $y$, el efecto desde el punto de vista castellano era un yeísmo de la $\tilde{n}$, ya que en lugar de $\tilde{n}(=n y)$ sólo se oiría $y$. Un caso claro de este fenómeno se documenta en el apellido Camaño o Alcamaño de un morisco oriundo de Portilla (despoblado situado cerca de las Cuevas de Almanzora, Almería): Luis Camaño (E28v) frente a Luis Alcamayo (F38r).

El yef́smo. Verificado el primer punto de nuestra hipótesis, es decir que las consonantes situadas ante $y$ se encontraban en posición implosiva en la pronunciación arábigo-granadina, veamos ahora casos de yeísmo aparente producidos por este proceso. En el Repartimiento de Almeria el nombre propio Abraén Alboyo $(236,260)$ es también Abrahén Albollo (389). En el mismo texto se lee: «dos tahullas de tierra en Pechina, que eran de Junía e del Alfaquí" (116), frente a "dos tahullas de tierra en la dicha Pechina, que eran de Jumilla e del Alfaquí" (119); la grafía "Junía» debe representar una pronunciación Juníya-Jumíya ${ }^{2}$. El pago granadino de Tafia Aliolia figura como Ṭafiyar al-'Ulyà "T Tafiyar la Alta» en una fuente árabe ${ }^{43}$, mientras que en el Libro de Habices hallamos, entre otras, las grafías «Tafiar Abulla» (170), «Tafiar Alhoya» (201n2). En los padrones murcianos el topónimo Alsodux (Almería), en árabe al-Sudus ${ }^{4}$, se transcribe normalmente Açuduz, pero un mismo morisco "natural de Çuduz» (A9r), es «natural de Suyuz en la Taha de Marchena» (B24r), mientras que otra morisca dijo ser «de Açollos de la

41 Pág. 210: «los prençipales y personas que entendían en lo que convia»; K. Garrad corrige acertadamente: «convenía».

42 Los intercambios $m-n$ en posición intervocálica no son infrecuentes en los arabismos. En el mismo texto hallamos: Abdarrani (225) por 'Abd al-Raḥmān; Onalfata (482) por Umm al-Fath; Açaframi (292) al lado de El Çafrani (402); Homey (360, 370) al lado de Honey $(361,365,366,368)$; etc.

43 TAI, pág. 72.

4 M. Asfn Palacios, Contribución a la toponimia drabe de España, MadridGranada, 1940, pág. 74. 
Taha de Marchena» $\left(\mathrm{B}^{\mathrm{r}}\right)$; el paso de $d$ a $y$ es sorprendente pero totalmente seguro ${ }^{45}$, y la conversión de $-y$ - en $-l l$ - será un caso de lleísmo por ultracorrección.

Algunos testimonios interesantes del yeísmo hispano-árabe aparecen en textos murcianos de los siglos XIV-Xv, los cuales normalmente mantienen la $/ \mathrm{l} / \mathrm{c}$ con total firmeza. Por aquel entonces el lugar de Alcantarilla estaba poblado de mudéjares, y en algunos pasajes referentes a ellos el topónimo se transcribe Alcantaria ${ }^{46}$. En otro documento de 1424 se compensa a un vecino por la pérdida de "un almadraque e una almadraquýa" ${ }^{47}$ que se habían utilizado para cerrar una brecha en la muralla de la ciudad durante una inundación provocada por el desbordamiento del Segura; debe tratarse de *almadraquilla, diminutivo de almadraque "colchón, almohada" ${ }^{48}$.

La antiguiedad de la debilitación de las consonantes implosivas en el hispano-árabe, y por consiguiente la temprana fecha de su "yeísmo", puede cambiar nuestro punto de vista con respecto al aparente yeísmo mozárabe detectado en ciertos topónimos y voces de este origen transmitidas a través del árabe hispánico. En vista de que los hispano-árabes pronunciaban la $/ / /$ mozárabe como $-l y$-, la posterior pérdida de la $-l$ implosiva dejaría una $-y$ - que le daría a la forma mozárabe un aspecto yeísta. Esta explicación sería válida, por ejemplo, para el topónimo Payares citado en el Repartimiento de Murcia ${ }^{49}$, procedente del latín PALEĀRĒS "los Pajares», y para la Ramble de Tiata, primitiva acequia mayor de la huerta de Lorca, de construcción seguramente romana, cuyo nombre parece proceder del latín TALEÃTA «la Cortada, la Tajada» > mozár. *Taláta > ár. *Talyāta, luego *Tayāta $>$ cast. *Teata, Tiata ${ }^{\text {*0 }}$. Los topónimos de este tipo no constituyen, por lo tanto, evidencia de que los mozárabes practicaran el yeísmo, sino que más bien atestiguan de nuevo el "yeísmo» hispano-árabe.

45 Cf. el topónimo Marmuyas (Comares, Málaga), probablemente derivado del árabe Mașmūda (ver: M. RIU, La cuarta campaña en el Cerro de Marmuyas, AlQanţara II (1981), págs. 431-2); F. Simonet halló noticias de un antiguo despoblado "Mazmuller, cerca de Comares, sobre una sierra» (Descripción del Reino de Granada, Madrid, 1860, pág. 168).

46 "los moros del Alcantaria" (doc. de 1353 en copia de hacia 1400: J. ToRres FoNTES, El regadio murciano en la primera mitad del siglo XIV, Murcia, 1975, pág. 57), y en 1397 un moro mudéjar procedente de «Alcantaría» se avecindó en Murcia (Actas Capitulares de 8-I-1397, fol. 13v).

47 Actas Capitulares de 25-I-1424, fol. 16r.

48 La voz almadraque, a pesar de considerarse masculino, forma sus derivados habitualmente en femenino: almadrequeja, almadraqueta.

49 Ed. preparada por J. Torres Fontes, Madrid, 1960, págs. 250-1.

50 Cf. el topónimo Tejada, despoblado situado a unos $30 \mathrm{~km}$. al noroeste de Sevilla, que se denomina Talyăța en textos árabes. 


\section{DESDOBLAMIENTO ARMONICO DE LAS VOCALES}

Se trata del sistema de abertura y cerrazón en armonía de todas las vocales de la palabra, que en el andaluz oriental se emplea para diferenciar: a) el singular del plural, b) la segunda persona del singular de la tercera en determinados tiempos del verbo, y c) algunos pares de voces. Todas estas formas se habían distinguido anteriormente mediante la presencia o ausencia de una $-s$ final, $u$ otras consonantes en esta posición.

El fenómeno, dado a conocer por primera vez por T. Navarro Tomás en $1939^{51}$, y cuidadosamente investigado en el habla de Granada por D. Alonso, A. Zamora Vicente y M. J. Canellada ${ }^{52}$, es ya generalmente conocido ${ }^{53}$. Todos los autores coinciden en señalar que se trata de una evolución sin precedentes en el castellano. Aparece sobre todo en las provincias de Granada y Almería, adentrándose en Murcia por el este, y en Córdoba por el oeste, mientras que no se percibe en la pronunciación de sevillanos, malagueños ni gaditanos ${ }^{54}$. Esta distribución geográfica corresponde bien a un rasgo originado y lentamente propagado desde el antiguo territorio del reino musulmán de Granada, aunque la ausencia del fenómeno en tierras malagueñas requeriría una explicación especial, acaso debiéndose a una diferencia dialectal dentro del árabe granadino.

Sin embargo, a la hora de buscar, en la pronunciación de los moriscos granadinos, evidencia de un comportamiento vocálico similar al del andaluz oriental, topamos con la dificultad de que el sistema gráfico castellano del siglo XVI no disponía de signos adecuados para representarlo aunque existiera, y sería de temer que el proceso de abertura y cerrazón hubiese quedado oculto detrás de transcripciones que forzosamente simplificaban la verdadera pronunciación de estos moriscos. Apenas quedaría testimonio alguno del fenómeno andaluz actual si se utilizaran tan solamente cinco vocales, sin signos diacríticos, para plasmarlo. Pero a pesar de estas limitaciones es posible detectar, en el

51 En una nota intitulada Desdoblamiento de fonemas vocálicos: Revista de Filología Hispánica, I (1939), págs. 165-7.

52 Vocales andaluzas, N. R. F. H., IV, núm. 3 (julio-sept. 1950), págs. 209-230.

53 Algunos ejemplos orientativos: a) sing.pl.: /djęntę/ - /djęntę/, /bọka/ /bớkä/, /ọlọrớsọ/ - /Qlọróso/, ęnẹrọ/ - /ęnęre/; b) 2.a - 3.a pers.: /bję́nę/ -

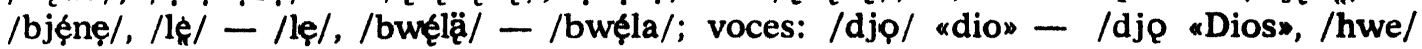
«fue» - /hwe/ «juez».

54 Vocales andaluzas, pág. 209. 
abundante material recogido en los padrones murcianos, la presencia del rasgo en cuestión en la pronunciación morisca. El topónimo Albanchez ejemplifica con claridad el proceso: cuando, en la forma transcrita por el escribano, la última sílaba (tónica) contiene la vocal É, las otras dos vocales son A (Albanchez, Albanchés, Almanchez, Albanchén) ${ }^{55}$, pero cuando la última vocal es $\mathrm{I}$, las primeras dos tienden a convertirse en E (Albechinze, El Beynchín, El Bechin, Albechín, Alvechín) ${ }^{56}$; en otros términos, la $E$ va acompañada por un vocalismo A-A-É, mientras que la I cierra las otras vocales hacia E-E-f. De modo similar, el topónimo Almócita, en árabe al-Mawsața o al-Mawsiț ${ }^{57}$, puede aparecer con su $A$ etimológica cerrada hasta $O$, $o$ incluso $U$ (por influencia de la $W$ siguiente); la $\mathbf{A}$ se rodea de un vocalismo A-A-A-A o A-A-E-A (Almauçata, Almauzata, Almaoçata, Almaoçeta, Almauçeta) ${ }^{58}$; la $O$ provoca A-O-E-A, (E)-O-E-A (Almoçeta, Almosseta, Almogeta, El Moçeta, Moçeta, Moseta, Mosseta) ${ }^{59}$; la U produce (E)-Ú-E-A (Museta) ${ }^{60}$; se puede suponer que la desaparición del artículo de algunas de las formas se debió a su pronunciación como /el/. En algunos topónimos detectamos un movimiento en armonía de las vocales átonas sin que afecte a la vocal tónica: por ejemplo Somontín (L157v) - Samatín (B47r) - Çimintín (E25r), o Belefique $\left(\mathrm{B} 9^{\mathrm{v}}\right)$ - Vilifique $\left(\mathrm{B} 52^{\mathrm{v}}\right)$ - Beilifiqui $\left(\mathrm{B5}^{\mathrm{r}}\right)$; en ambos casos la vocal tónica es 1 , y en ella la amplitud del movimiento de abertura y cerrazón debió ser menor, como lo es en el andaluz oriental. En otros topónimos el número de testimonios es demasiado reducido para que se puedan sacar conclusiones estadísticamente válidas. Así, el morisco Lorenço Almaquibar $\left(\mathrm{M}^{\mathrm{r}}\right.$ ) se llama en el mismo folio Lorenço Mequibe, cambio que recuerda el andaluz azuque por azúcar; pero desgraciadamente este hombre no reaparece en ninguna otra lista.

A pesar de las dificultades, se ha podido observar en la pronunciación de los moriscos una clara tendencia a abrir o cerrar las distintas vocales de un nombre conjuntamente, en armonía, de la misma manera que lo hace el andaluz oriental. Pero existe una diferencia importante. En el andaluz la variación vocálica tiene valor fonológico, sirviendo para modificar el significado de las voces, mientras que en el árabe granadino no debía de tener este valor (ạl menos en principio): el topónimo

\footnotetext{
55 Muy frecuente; B37v, E32r; B54r; F5v.

56 C2v; L153v; L108r; C14v, L170r; L12r.

57. M. GoMez-Moreno, op. cit., pág. 35.

58 F12r; H1r; F23r; B5r; B5v, L170v.

59 B9v, L126v, L201v; L61v; L146v; L124r; L137v, L142r; L46v; L31v.

60 L53v. Unicamente la forma Almoçate (D18v) no encaja, y pienso que podría carregirse Almoçeta.
} 
Albanchez no es diferente de Albechinze, y Çimintín es lo mismo que Somontín. Al parecer la variación armoniosa de las vocales en la pronunciación arábigo-granadina responde simplemente a la mayor libertad de articulación de las vocales que permite la fonología árabe, que sólo tiene tres fonemas vocálicos (A-I-U) frente a los cinco castellanos, y tolera grandes modificaciones en las vocales átonas. No obstante, pudiera ser que los moriscos granadinos, por algún motivo que habría que dilucidar, al hablar en castellano, aprovechasen su capacidad de abrir y cerrar armoniosamente las vocales para distinguir entre el singular y el plural, etc., debido a su incapacidad de pronunciar bien las consonantes finales que determinaban estas diferencias en el castellano.

Acaso la pista decisiva para resolver esta cuestión se encuentre en la pronunciación morisca del topónimo Albanchez, ya que aquí la variación armoniosa de las vocales va acompañada de una modificación en la consonante final: encontramos A-A-E cuando la consonante final es - $s$ o - $z$, y A-E-1 o E-E-1 cuando ésta es - $n$ (en un caso -nze). Ahora es una característica muy conocida del árabe la variación alofónica de las vocales de acuerdo con el entorno consonántico: unas consonantes provocan una articulación más cerrada de las vocales más próximas (imela), mientras que otras impiden este proceso, dejando una pronunciación más abierta. En el caso concreto del topónimo Albanchez observamos que la $-n$ cierra las vocales y la $-s /-z$ las abre. Y éste es precisamente el comportamiento que se detecta en el andaluz oriental: en la conjugación del verbo, por ejemplo, la $-s$ final de la segunda persona del singular y la primera persona del plural abre las vocales, mientras que la $-n$ de la tercera persona del plural las cierra: / tję́nę/ "tienes» /tjénẹ̃n/ «tienen», /sơmo/ «somos" - /sọ̃n/ «son», /le्্// «lees" /lện/ «leen», etc. ${ }^{61}$. Entonces, de acuerdo con nuestra hipótesis, los árabes granadinos, al pronunciar el castellano, articularían las vocales de las palabras más abiertas o más cerradas según la consonante final. Y en vista de la debilidad de las consonantes finales en su propia pronunciación, esta variación vocálica ya sustituiría, al menos en parte, a la consonante final en sus funciones fonológicas, igyal que lo hace actualmente en el andaluz oriental ${ }^{62}$.

61 Vocales andaluzas, págs. 2234.

62 Estas conclusiones no pasan de ser muy provisionales. La escasez de los datos a' nuestra disposición nos impide avanzar más en la clarificación de cómo la armonfa vocálica arábigo-granadina se pudo convertir en el fenómeno andaluz a través de la pronunciación de los moriscos aljamiados. Un problema muy concreto que queda, por el momento, sin solución es el comportamiento de la A andaluza en la última ślaba, ya que una $-s$ siguiente la cierra mientras que esta misma 


\section{NEUTRALIZACION DE L/R EXPLOSIVAS AGRUPADAS}

El fenómeno, estudiado detalladamente por F. Salvador Salvador ${ }^{63}$, consiste esencialmente en la conversión de los grupos iniciales bl-, cl-, $f l-, g l-, p l-$ en $b r$-, $c r$-, $f r-, g r-, p r$ - en la provincia de Granada, y zonas limítrofes de Málaga, Córdoba y Almería. Aunque se trata de un rasgo característico del portugués, gallego y dialectos afines, el fenómeno andaluz-oriental se halla aislado geográficamente del área en la que se hablan dichas lenguas y dialectos. F. Salvador atribuye su presencia en Granada a la llegada de importantes contingentes de repobladores gallegos y leoneses en los siglos XVI-XVII, de cuyo lenguaje esta neutralización era y es una característica conocida. Sin embargo, conviene tener presente que los grupos iniciales de consonantes no existen en el árabe, por lo que su articulación les causaría dificultades a los moriscos, mientras que la distribución geográfica del rasgo en Andalucía Oriental apoyaría la hipótesis de una actuación del sustrato arábigo-granadino. Debido a la ausencia de los mencionados grupos en el árabe, no podemos buscar casos de neutralización en el material onomástico empleado en este estudio para establecer los demás rasgos de la pronunciación de los moriscos granadinos. No obstante, aparecen testimonios claros del fenómeno en el Memorial de Núñez Muley, redactado en 1567, con anterioridad a las migraciones gallegas y leonesas mencionadas por F. Salvador: Frandes (205), empreados (209 dos veces), escresiástica (212), pranta (217).

consonante abre las demás vocales. Por ejemplo: /ba/ «va» - /bä/ «vas» - /bãy/ "van», /mớha/ «moja» - /mớhä/ «mojas» - /mớhã/ «mojan» (Vocales andaluzas, loc. cit.). Ello podría resultar de un tratamiento especial de la vocal A por el andaluz, pero también existe la posibilidad de que se deba al empleo por parte de los moriscos de una sibilante distinta para representar la $S$ final castellana tras A. Sabemos que acostumbraban utilizar su $\$$ palatal para representar aproximadamente la $S$ castellana. El uso de esta sibilante tras A en posición final tendería a convertir dicha vocal en /e/ (por imela), justamente el reflejo que se detecta en el andaluz oriental. Pero si hubiesen utilizado la misma $\delta$ tras E/O finales, estas vocales se habrían inclinado hacia la pronunciación $/ \mathrm{i} / \mathrm{h} / \mathrm{u} /$, por la misma causa, y debido a esto quizás evitarían la $\boldsymbol{\zeta}$ tras $\mathrm{E} / \mathrm{O}$, utilizando en su lugar la Ș velarizadora para conseguir mejor los sonidos /e/ y /o/. No obstante, es demasiado pronto para intentar llegar a conclusiones firmes sobre tales cuestiones.

63 F. Salvador Salvador, La neutralización $l / r$ explosivas agrupadas y su área andaluza, Univ. de Granada, 1978 (esp. págs. 255-259). 
CONVERSION DE $A$ FINAL ATONA EN $E$

Nos referimos a la pronunciación de la - $a$ final absoluta átona como /e/, esporádicamente en puntos inconexos de la Andalucía oriental, y de manera sistemática en el Valle de Lecrín (Granada); el rasgo fue detectado por los encuestadores del Atlas Lingüístico-Etnográfico de Andalucía, y descrito por A. Llorente Maldonado en su artículo Fonética $y$ fonología andaluzas ${ }^{64}$. La pronunciación de la -a final átona como /e/ es característica de ciertos dialectos árabes, y parece haber ocurrido en alguna medida en el árabe granadino según lo que se desprende de los datos proporcionados por el material onomástico examinado. El fenómeno es especialmente frecuente en el Repartimiento de Almeria: Abenexme $(172,327)$ al lado de Abenexma $(174,210)$, Mahomad Caçile (314) pero Mahoma Caçila (332), Çad Çuaye (367) pero Çad Çuaya (466), Ali Chureila $(183,438,469)$ frente a Mahoma Açueile (457), Yahi Xexa (160) pero Xexe (118) y Ali Xexe (164), etc. ${ }^{65}$.

\section{ENSORDECIMIENTO DE $B$ POR UNA $S$ ASPIRADA ANTERIOR $(S B>F)$}

Como se sabe, en ciertas hablas meridionales del castellano la aspiración de la $-s$ implosiva va acompañada por el ensordecimiento de una $b, d$ o $g$ siguiente. El efecto se nota especialmente en la $b$, que parece convertirse en / $f$ / (si bien se trata en realidad de una $f$ bilabial): lah fótah «las botas», dehfán «desván», etc. Entre las conclusiones provisionales sacadas por M. Alvar de las primeras encuestas realizadas para el Atlas Lingüístico-Etnográfico de Andalucia cabe destacar la división de Andalucía en dos zonas con respecto al tratamiento de los grupos $-s b$-, $-s d-$ y $-s g$. En las provincias orientales y Murcia, la segunda consonante tiende a ensordecerse, pero en la zona occidental se mantiene prácticamente inalterada ${ }^{\circ}$. Estamos, por lo tanto, ante otro rasgo

64 R. F. E. XLV (1962), pág. 233.

65 Estas grafías, más que indicar una pronunciación vacilante entre /a/ y /e/, representarán un sonido intermedio que en otras ocasiones ni siquiera se oyó: frente a Çuaya, Çuaye encontramos Xuay (383); al lado de Chureila está Chuleil (395); y junto con Xexa, Xexe aparece Xes $(210,212)$.

66 M. Alvar, Las encuestas del «Atlas lingilitstico de Andalucia* (Diciembre 1953. Marzo 1955), Revista de Dialectología y Tradiciones Populares, XI, 1955, Cuaderno $3 .^{\circ}$, págs. 245-7.

LXVI, $1.0-2.0-7$ 
característico del andaluz oriental, el cual se debió extender hacia las comarcas limítrofes (el fenómeno no es antiguo en Murcia, pues en los documentos del siglo $\mathrm{XV}$ no se encuentra ningún indicio de $s b>f$, ni de la aspiración o debilitación de la $-s$ implosiva). El primer testimonio castellano de este rasgo es la conocida transcripción Sofonifa, por Sophonisba, de Fernando Colón, hijo del descubridor; no sabemos dónde, ni a quién, oyó esta pronunciación. Pero en el árabe hispánico este cambio fonético es mucho más antiguo: Ibn Quzmān (1078-1160) ya escribe kasfūra por kazbūra «cilantro» ${ }^{67} \mathrm{y}$, como señala J. M. Pabón, el pueblo granadino de Esfiliana, ya denominado Ixfiliana en alguna fuente árabe según Simonet, sería en su origen la finca de un Išbītī o sevillano ${ }^{68}$. Por otra parte también hallamos instancias del fenómeno paralelo -sp- > -sf- (sabido es que muchos sub-dialectos del árabe hispánico conocían y pronunciaban el fonema $/ \mathrm{p} /$, sobre todo en vocablos y topónimos de procedencia romance): el latín ASPARAGUS dio el hisp.ár. isfarāy, forma que se recoge en el Glossarium latino-arabicum del siglo $\mathrm{XI}^{69}$, y aunque $\mathrm{P}$. de Alcalá y el Vocabulista levantino indican una pronunciación isbarany o isparany, no obstante fue isfarā $\hat{y}$ la variante que se estableció definitivamente en el norte de Africa ${ }^{70}$. Y en el Repartimiento de Almería (1498-1504) aparece el antropónimo al-'Așfī "él de Aspe transcrito Alasafi $(429,456)$, Alasfín (335), frente a Ala Pín (333); en los padrones murcianos hallamos Alonso Alcarfí (P32v) al lado de Alonso Alquerpí (B7v); y M. Asín Palacios da como etimología del topó-

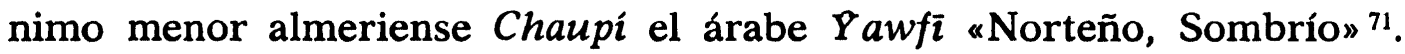

\section{Discusión.}

Dificultad Del yefsmo moRisco. De todos los rasgos andaluces que hemos propuesto relacionar con el sustrato arábigo-granadino, el más problemático y cuestionable es el yeísmo. En 1951, cuando Amado Alon-

67 Sketch, pág. 32, sección 2.1.2.

68 Sobre los nombres de la «Villa»..., pág. 137. Sería, sin embargo, más aceptable partir de un étimo pre-árabe "HISPALIĀNA "(Villa) del Sevillano», ya que el hispano-árabe no parece que conociera el sufijo -(i)āna.

6 C. F. SEYBold, Glossarium latino-arabicum ex unico qui exstat codice leidensi undecimo saeculo in Hispania conscripto, Berlín, 1900, pág. 5.

70 R. Dozy, Supplément aux dictionnaires arabes, Leiden, 1881 (reproducción en facsímil, Beirut, 1968), tomo I, pág. 22. En su libro Los mozarabismos del Vocabulista atribuido a Ramón Martí (Madrid, 1961, pág. 240) David Griffin excluye esta voz de la lista de verdaderos mozarabismos, supongo por motivos fonéticos; pero pudo ser autóctono ya que se da el paso de $g^{u}$ mozárabe a $y$ árabe en Espana (p. ej. TAGUS $>$ Tãouh $>$ Tajo), y también el traslado del acento a la última sílaba en el hispano-árabe.

71 Contribución a la toponimia árabe de España, pág. 103. 
so publicó su fundamental estudio sobre $L a$ «ll» $y$ sus alteraciones en España y América, pudo concluir, según los datos entonces conocidos, que el yeísmo andaluz nacería y se extendería a partir del año 1700 aproximadamente ${ }^{72}$. Tal conclusión, de confirmarse, sería totalmente incompatible con una procedencia arábigo-granadina del fenómeno, ya que, para tener este origen, el yeísmo tendría forzosamente que estar arraigado en el habla andaluz-oriental con anterioridad a 1570, año de la expulsión de los moriscos del Reino de Granada y fecha tope para la actuación del sustrato árabe. Por otra parte, existen testimonios aparentemente categóricos de que los moriscos no eran yeístas: en la Guerra de Granada se identificaba a los moriscos de lengua materna árabe obligándoles a decir cebolla, a lo que respondían xebolia, y no xeboya; y los dramaturgos de los siglos XVI-XVII a menudo aprovechaban la mala pronunciación de los moriscos para conseguir risas fáciles, pero el yeísmo no era, sin embargo, uno de los rasgos utilizados por ellos con este fin ${ }^{73}$. Finalmente, desconocemos hasta qué punto pudieron influir en el desarrollo del yeísmo andaluz los otros brotes yeístas y lleístas, anteriores o contemporáneos con la reconquista y repoblación del Reino de Granada, que se han detectado en diferentes regiones castellanas ${ }^{74}$; desde estos lugares verosímilmente acudirían nuevos pobladores portadores de la simiente del yeísmo a las tierras andaluzas.

En cuanto a la posible fecha tardía del yeísmo andaluz, testimonios aislados de éste han ido apareciendo que prueban su mayor antigüe$\operatorname{dad}^{75}$. Son de especial interés los casos de yeísmo, y su ultracorrección el lleísmo, ambos involuntarios, en dos fuentes literarias: el cancionero de Pedro del Pozo (1547), y la Historia de la doncella Arcayona, compuesta en Túnez por un morisco de los expulsados en 1609. El primer texto muestra, además del yeísmo, seseo-ceceo y la pérdida de -r final (llorá «llorar»), y se deberá, como indica R. Lapesa, a un autor andaluz; A. Galmés de Fuentes, en su estudio del segundo texto, asimismo indica Andalucía como probable patria del autor, en vista de la abundancia de casos de seseo frente a la ausencia de rasgos linguísticos aragoneses o valencianos ${ }^{76}$. La teoría de A. Alonso de que el yeísmo

72 Recogido en sus Estudios lingüísticos - Temas hispanoamericanos, B. R. H. II, 12, Gredos, 3. a edición, 1.a reimpresión, 1976, pág. 206.

73 Ver: A. E. Sloman, The phonology of Moorish jargon in the works of early Spanish dramatists and Lope de Vega, Modern Language Review, XLVI, 1949, páginas 207-217.

74 J. Corominas, Para la fecha del yeísmo y del lleísmo, Tópica Hespérica, tomo I (B. R. H. II, 169), Gredos, Madrid, 1972, págs. 321-331.

75 R. LAPESA, Historia de la Lengua Española, B. R. H. III, 45, Gredos, Madrid, 1980, págs. 382-5.

76 Lle-yeísmo y otras cuestiones, págs. 274-5. 
andaluz se desarrolló en fechas muy tardías estaba fundamentada principalmente en el testimonio ex silentio de un buen número de gramáticos andaluces, y otros que conocían la situación linguiística en Andalucía en los siglos XVI-XVII, los cuales, aunque se ocupan frecuentemente de la pronunciación vulgar y regional, nunca hacen la más mínima alusión a la existencia del yeísmo-lleísmo. Ahora, en primer lugar, esto resulta muy difícil de reconciliar con el hecho de la existencia de escritores yeístas que debieron vivir en alguna parte de Andalucía durante el período en cuestión: sólo si se tratara de personas incultas, habitando en zonas rurales y apartadas, se podría comprender que los gramáticos desconocieran por completo su modo de hablar a pesar de vivir en la misma provincia que ellos. Pero al comprobar, una por una, las patrias naturales o adoptivas de cada gramático $u$ hombre de letras citado por A. Alonso, llegamos a la significativa conclusión de que ninguno vivió ni trabajó en la zona que nos interesa, ni hace referencia a ella: proceden de Sevilla, Córdoba, Extremadura, Jaén, La Mancha y Murcia, pero ninguno es de Málaga, Almería o Granada ${ }$. Y así ninguno de ellos tenía por qué conocer la situación lingüística en las tres provincias reconquistadas a finales del siglo $\mathrm{xv}$, de modo que el testimonio ex silentio de la ausencia del yeísmo no puede entenderse como válido para las dichas tres provincias. Por otra parte es relevante el hecho de que, según los datos de A. Alonso, el primer hombre de letras que reconoce, ya en el primer cuarto del siglo XIX, que no sabe distinguir entre $l l$ y $y$, procede justamente de una de estas tres provincias: "el ortólogo Mariano José Sicilia, Canónigo de Baza (Granada) y catedrático de Granada». Para él, en palabras de A. Alonso, «el yeísmo era la práctica general de la lengua, y la distinción $l l-y$, sólo práctica castiza de alguna región conservadora (los castellanos viejos sobre todo) ${ }^{78}$.

Por otra parte, el hecho de que los moriscos dijeran xebolia, y no xeboya, no es especialmente significativo. La pérdida de las consonantes implosivas debió ser un rasgo de su pronunciación cotidiana y descuidada, que sabrían corregir (y a veces ultracorregir) en situaciones formales, como ante el escribano o un oficial que les obligara a decir cebolla. En nuestras fuentes onomásticas las consonantes implosivas

$\pi$ Corresponden a Sevilla: ¿Nebrija? (1517), Cristóbal de las Casas (1570), Mateo Alemán (1609), Ambrosio de Salazar (1614), Juan de Robles (1631), Juan Villar (1651); a Córdoba: Francisco Delgado (1534), Juan Sánchez (1586), Bernardo de Aldrete (1606-14), Juan Bautista de Morales (1623); a Extremadura: Gonzalo Correas (1626), Gonzalo Bravo Graxera (1634); a la tierra de don Quijote, ya cercana a Sierra Morena: B. Ximénez Patón (1614); a Jaén: Juan Villar (1651); y a Murcia: Ambrosio de Salazar (1614), D. Nicolás Dávila (1631), Francisco Cascales (1634).

78 La «ll» y sus alteraciones, pág. 174. 
a menudo se hallan pronunciadas correctamente, lo que demuestra que los moriscos aún sabían más o menos cuáles correspondían a cada palabra y cómo articularlas; pero los muchos errores demuestran que habitualmente las pronunciaban poco y mal (son comparables las cacografías del tipo Bilbado "Bilbao" o fisno "fino", las cuales demuestran que el sujeto a la vez sabe decir la - $d$ - intervocálica de la terminación -ado, o la -s implosiva, pero que normalmente no lo hace). Así, en una situación formal el morisco sabría repetir xebolia, intentando reproducir el castellano cebolla, pero en una conversación relajada y natural tendería a decir xeboya.

La tercera dificultad que hemos planteado con respecto al "yeísmo» de los moriscos granadinos es la ausencia de este fenómeno en la jerga morisca de las obras literarias de los siglos XVI-XVII. Albert Sloman, en su citado estudio, señala que las deformaciones más frecuentemente puestas en boca de los moriscos eran: a) el xexeo; b) conversión de $/ \mathrm{p} /, / \mathrm{k} /$ en $/ \mathrm{b} /, / \mathrm{g} /$; c) conversión de $l l, \tilde{n}$ en $l i, n i ; d)$ confusión de las vocales y simplificación de los grupos vocálicos. Por nuestra parte, en el material onomástico hemos hallado no solamente el xexeo, sino también la confusión de todas las sibilantes, tanto fricativas como africadas: seseo, ceceo, checheo, jejeo y xexeo. Se atestigua el paso de /k/ a /g/ y su ultracorrección ${ }^{79}$, pero no es normal la conversión de /p/ en /b/: topónimos como Pechina, Purchena, Padules o Paterna pueden sufrir diversas alteraciones, pero siempre conservan su $/ \mathrm{p} /$, lo que sugiere que la /p/ hispano-árabe debió ser especialmente estable en el dialecto granadino. La vacilación $\tilde{n}-n i$ y $l l-l i$ y el desorden vocálico son, asimismo, frecuentes en la pronunciación de los moriscos granadinos, como ya se ha visto. Pero se detectan también otros rasgos que los dramaturgos no solían emplear para caracterizar a sus personajes moriscos. Sin duda los más importantes son la debilitación y pérdida de las consonantes implosivas y el yeísmo, pero también cabría agregar la caída de la vocal final átona, la confusión de $r-r r$ y $m-n$ explosivas, y la introducción de vocales epentéticas para abrir grupos de consonantes ('Așfī > Asafi).

La falta de estos rasgos en las caracterizaciones teatrales podría deberse a diversas causas. Por una parte, existirían diferencias dialectales entre el árabe hablado en distintas zonas de la Península en el siglo XVI, y los autores castellanos probablemente conocerían menos la pronunciación de los moriscos granadinos que la de los moriscos castellanos - los antiguos mudéjares-, cuya lengua árabe acaso no había

79 Cf. Cariaga-Cariaca. 
llegado a los extremos de desarrollo fonético y fonológico alcanzados por el árabe granadino. Pero al mismo tiempo es preciso considerar la relativa fiabilidad de las dos fuentes. Los rasgos utilizados en las obras de teatro seguramente remontaban a una observación inicial de la pronunciación de los mudéjares o moriscos aljamiados de lengua materna árabe. Sin embargo, como observa Sloman, no se puede esperar encontrar una representación exacta de su modo de pronunciar en una jerga teatral que, más que reproducir, exagera, e incluso incorpora elementos ajenos: se formula un conjunto de reglas que el dramaturgo aplica fiel y acríticamente ${ }^{80}$. Frente a esto, los materiales onomásticos estudiados aquí resultan de una transcripción inmediata de una observación directa y objetiva de la pronunciación de unos moriscos cuyo lugar de origen podemos determinar exactamente. Por lo tanto, estos datos son mucho más relevantes y fidedignos.

Resulta, por el contrario, curioso que los rasgos empleados para caracterizar la pronunciación de los negros en las mencionadas obras recuerdan de manera notable la pronunciación de nuestros moriscos: yeísmo y la pérdida de las consonantes implosivas, entre otros. Sabido es que en el siglo XVI abundaban los esclavos de color negro en el Reino de Granada, y pudiera ser que los negros en cuya pronunciación se basaban los dramaturgos para sus caracterizaciones aprendieran su «castellano» en Andalucía oriental antes de ser exportados a Castilla.

En resumen, el yeísmo andaluz, antes de emprender una expansión que ahora amenaza con desterrar la / $/$ / de todo el ámbito castellano, debió tener su humilde origen y principal epicentro en la zona correspondiente al antiguo reino musulmán de Granada, reconquistada a finales del siglo xv. La fecha tardía de la consolidación de este yeísmo, que no llamó la atención de los hombres de letras hasta bien entrado el siglo XVIII, se deberá a un largo período de incubación como fenómeno del lenguaje informal y descuidado, recluido dentro de las tres provincias del antiguo Reino de Granada. El nacimiento y primer desarrollo del rasgo en este pequeño territorio podría atribuirse parcialmente a la abigarrada procedencia de los repobladores (excelente caldo de cultivo para las innovaciones linguísticas), algunos de los cuales pudie-

80 En las palabras de Sloman: «There were rustics, negroes and Moors in Spain whose speech could be heard and, if dramatists were so inclined, studied. But, though derived from fact, it is idle to look for any strictly accurate presentation of speech characteristics. Stage jargon is a fancy dress which exaggerates rather than reproduces, and often admits extraneous elements. The idiosyncrasies of the language of each type are caricatured and conventionalized. A set of rules is formulated for each which the dramatist follows as closely as any cook his recipe» (op. cit., pág. 208). 
ron traer el yeísmo consigo desde sus pueblos de origen. Pero frente a esta posibilidad, por el momento puramente hipotética aunque no inverosímil, tenemos el hecho, documentalmente comprobado, del extraño "yeísmo-lleísmo» de los moriscos granadinos. Durante ochenta años los nuevos pobladores castellanos convivieron con éstos, exactamente en las tierras en las cuales se consolidó, y desde las cuales se propagó, el yeísmo andaluz. No es posible probar de modo concluyente que la pronunciación de los dichos moriscos fue la causa directa del desencadenamiento del yeísmo, pero indudablemente se daban, en aquellas tierras, por aquel entonces, todas las condiciones para que así sucediera.

Paso de los rasgos del arabe al castellano. Habiendo establecido el hecho de que varias de las principales peculiaridades fonéticas y fonológicas del andaluz oriental ya caracterizaban el dialecto árabe hablado en las mismas tierras antes de la implantación del castellano, resta por esclarecer de qué manera estos rasgos lograrían pasar de un idioma al otro.

Como ya se ha dicho, las dos lenguas convivieron entre los años 1492-1570. Durante todo este período la repoblación castellana fue poco densa en los campos donde la mayor parte de la población, quizás el $90 \%$, siguió siendo morisca, y fue, sin duda, en estas zonas rurales donde la mala pronunciación de los moriscos aljamiados empezó a influir sobre la lengua de la minoría castellana. Pero ¿por qué imitarían los castellanos la pronunciación de este pueblo vencido? Creo que es importante tener en cuenta la fascinación que causaban, en esta época, los acentos raros y deformaciones de la lengua, sobre todo cuando se trataba de las que perpetraban moriscos, gitanos o negros, cosa que se desprende de su utilización hasta la saciedad, en obras de teatro o poemas, como truco para conseguir risas fáciles, y no habría de sorprendernos que el pueblo llano hiciera lo mismo en su casa, o entre amigos. Al principio se copiaría la pronunciación en broma, pero la broma se convertiría en hábito en algunos estratos de la lengua, afincándose y propagándose paulatinamente, no sólo antes sino también después de la marcha de los moriscos. Se me objetará que no es creíble que la pronunciación de un pueblo humillado y despreciado influyera de tal forma sobre el habla de otro superior y vencedor, pero ¿no sucedió algo muy similar en la propagación del yeísmo andaluz, que durante los siglos xviri-Xix pasó de ser un rasgo regional, rústico y vulgar a convertirse en característica del castellano de muchas de las principales ciudades españolas? ${ }^{81}$.

81 La facilidad con la que se contagiaba la pronunciación morisca queda ejemplifi- 


\section{Conclusiones.}

Se ha examinado la posibilidad de que seis importantes características fonéticas y fonológicas, surgidas en el castellano implantado en Andalucía oriental tras su reconquista, se debieran a la influencia de sustrato del árabe granadino, en cuya pronunciación dichos rasgos ya estaban presentes con anterioridad a la llegada de los castellanos. De los seis fenómenos, cuatro se pueden atribuir directa o indirectamente a la debilitación y pérdida de las consonantes finales de sílaba en el hispano-árabe. El mismo proceso también afectaba el castellano bajomedieval, aunque en menor grado, y su presencia simultánea (pero independiente) en el hispano-árabe y el castellano podría achacarse en última instancia al sustrato ibérico común ${ }^{82}$.

El paso de las seis características del árabe granadino al castellano a través de la defectuosa pronunciación de los moriscos aljamiados durante el período de convivencia de 1492-1570 debió ser propiciado por la moda de imitar y ridiculizar la manera de hablar de los moriscos en las obras de teatro, actividad que también practicarían los particulares en su vida cotidiana, hasta el extremo de que la novedad se hiciera costumbre, provocando cambios irreversibles en ciertos estratos de la lengua los cuales se extenderían poco a poco a todos los hablantes de la región. Estas conclusiones no pueden dejar de sorprendernos. Se basan, no obstante, en hechos bien documentados, y dudar de ellas supone achacar un crecido número de ajustadas coincidencias a la casualidad.

\section{ROBERT POCKLINGTON}

\footnotetext{
cada en unos casos curiosos de yeísmo de $\tilde{n}$ (fenómeno morisco descrito más arriba, debido a su pronunciación de la $\tilde{n}$ como $n y$, convertido en $y$ por la pérdida de la - $n$ implosiva) que aparecen en el texto castellano de algunos de los registros de moriscos: «La casa de Miguel Sánchez Alachar: se halló en ella una hacha de hazer leya" (Visita, 262); "de hedad de diez años, seyalado en la cara con una ese y un clauo» (B4r), «es una moça gruesa, seyalada en la cara con seyales de uirgüela» (B4r), «cariaguileña» pero en el mismo folio «cariaguileya» dos veces (B5r), «la cara aguileya» (B5v). Estos últimos ejemplos murcianos se manifiestan tan solamente tres años después de la llegada de los primeros moriscos expulsados en 1570. De forma similar, en el Repartimiento de Almería, redactado sólo diez años después de la llegada de los castellanos, ya encontramos algunos casos de yeísmo: sin realizar una búsqueda sistemática he observado casiya acasilla» $(323,329)$ y Morataya (243, 262); no me consta que el pueblo murciano de Moratalla jamás haya sido yeista.

82 Manuel Alvar ya indicó la presencia de casos de pérdida de $-s$ final en inscripciones latinas procedentes de Málaga y Sevilla, planteando su posible relación con el dialectismo moderno (Las hablas meridionales de España y su interés para la lingüistica comparada, R. F. E. XXXIX (1955), pág. 288).
} 